\title{
O quem da educação a distância
}

\author{
Estrella Bohadana
}

Universidade Estácio de Sá, Programa de Pós-Graduação em Educação

\section{Lílian do Valle}

Universidade do Estado do Rio de Janeiro, Faculdade de Educação

Tornou-se um repisado truísmo afirmar que a rápida expansão, ${ }^{1}$ nos últimos anos, das iniciativas de educação a distância (EAD) ${ }^{2}$ em todos os níveis de

${ }^{1}$ O Censo da Educação Superior de 2006, divulgado pelo Instituto Nacional de Estudos e Pesquisas Educacionais Anísio Teixeira (INEP), revela que o número de cursos a distância no país cresceu 571\% entre 2003 a 2006 e o de matrículas aumentou 315\%. Em 2003, 52 instituições ofereciam essa modalidade de ensino superior. Em 2006 esse número saltou para 349. As matrículas passaram de 49.911 para 207.206. O censo mostra que, em 2005, os alunos de educação a distância representavam 2,6\% do universo dos estudantes universitários do país. Em 2006, a participação aumentou para 4,4\%.

${ }^{2}$ O que hoje conhecemos como “terceira geração" de EAD surgiu com o advento do microcomputador, que, rompendo com a comunicação baseada na bipolaridade característica das gerações anteriores, funda o fenômeno da comunicação em rede. O curso por correspondência - dito a "primeira geração de EAD” - é considerada, pela literatura especializada, a forma mais antiga de ensino a distância, tendo como tecnologia de suporte o material impresso. Com o advento do rádio, seguido da televisão, surge o que seria já a “segunda geração”, que permite a realização de emissões radiofônicas e televisivas - entre as quais os famosos ensino brasileiro, mas muito particularmente no ensino superior, teve como condição essencial o não menos notável desenvolvimento da informática no país. ${ }^{3}$

Mas a disseminação da EAD on-line no Brasil muito deve, também, à boa receptividade e aos incen-

telecursos. No topo desses avanços, e cada vez mais poderosos, os microcomputadores apresentam recursos sofisticados, permitindo a comunicação direta com outros microcomputadores por meio de redes locais e de longa distância.

3 Em meados de 1980, a internet passou a ser utilizada em vários países da Europa e nos Estados Unidos, principalmente nas universidades e em algumas empresas. As primeiras utilizações eram realizadas com terminais conectados por via telefônica a universidades europeias e americanas, restringindo-se, na maioria dos casos, a consultas documentais e troca de $e$-mails (Almeida, 2005). No Brasil, a internet foi inaugurada em 1992, tendo sido viabilizada pela Rede Nacional de Pesquisa (RNP), que interligava as principais universidades e centros de pesquisa do país, além de algumas organizações não-governamentais. O uso comercial,porém, só foi liberado em 1995 e em maio do mesmo ano o Ministério da Ciência e Tecnologia criou o Comitê Gestor da Internet (CGI.br) para fomentar o desenvolvimento de serviços no Brasil. 
tivos com que as autoridades públicas brasileiras acolheram as novas possibilidades de atuação educativa em larga escala, além, é claro, do grande entusiasmo com que, em razão dos mais diferentes interesses, as novas orientações oficiais foram desde então sendo acolhidas, sobretudo pelas instituições privadas de ensino superior, ainda que não apenas aí.

Essa confluência de disposições positivas - já testemunhada em outros países desde 1996 - permitiu que, em breve lapso de tempo, a EAD passasse, de recurso marginal e pouco frequente, a menina dos olhos das políticas públicas e das ações empresariais levadas a cabo na atualidade. ${ }^{4}$ Hoje, diferentemente do que ocorria há apenas uma década, não é mais possível desconsiderar o impacto que a introdução da EAD online causou e as transformações que certamente ainda ocasionará em nossas formas correntes de conceber e de praticar a educação e a comunicação.

${ }^{4}$ Diferentemente do que ocorreu em suas origens, quando foi basicamente consagrada aos cursos técnicos ou de treinamento, e dos anos 1970-80, quando estava voltada para atender aos alunos que não haviam completado o segundo grau, a EAD informatizada, de meados dos anos 1990, visa essencialmente à formação do terceiro grau - justificando, assim, o constante aumento de universidades a distância por todo o mundo. Em 2001, Börje (apud Peters, 2004) listou a existência de 26 países que ofereciam ensino a distância para o terceiro grau. Seis anos depois, 60 países já possuíam suas universidades abertas. Uma das pioneiras foi a Universidade Aberta do Reino Unido, a Open University, criada há mais de 30 anos e que atende atualmente a cerca de 200 mil alunos. Mas encontra-se na Índia a maior universidade aberta do planeta, a Universidade a Distância Indira Gandhi, que conta com 1,5 milhão de alunos. Otto Peters (2004) chama a atenção para o fato de existirem, além dessas duas universidades mencionadas, pelo menos mais oito com corpo discente de 200 mil estudantes. Ressalta, ainda, que essas universidades a distância tornaram-se bem maiores, quanto ao número de alunos, do que as universidades totalmente presenciais. O autor refere-se mais especificamente às seguintes instituições: a FernUniversität, na Alemanha: a Universidade Nacional de Educação a Distância, da Espanha; a Universidade do Ar, no Japão; a Universidade Aberta, em Portugal; a Télé-Université, no Canadá; a UNA, na Venezuela; a Universidade Payame Noor, no Irã; e a Universidade da África do Sul.
Mas o consenso parece se esgotar aí. Para seus mais convictos adeptos, a vertiginosa conversão de disciplinas e cursos inteiros de nível superior à “modalidade não-presencial” a que o país assistiu, a partir de 1999, ${ }^{5}$ corresponde a uma "necessidade de mercado”, especialmente acentuada nos estratos formados por "milhares de jovens e adultos que enfrentam problemas criados pelo tempo ou [pelas] distâncias para completar sua formação escolar” ou por profissionais que buscam oportunidades de educação continuada (Universia, 2004). Pelas mesmas razões, seus mais atilados críticos denunciam os riscos de agravamento das desigualdades educacionais já produzidas a cada vez que se visou a uma rápida expansão de “oportunidades” medidas em resultados estritamente quantitativos.

Dever-se-ia assim, de fato, aceitar o que está implícito em ambas as posições: de que a EAD on-line responde essencialmente à proposta de fazer mais para quem pode menos - e tão somente esse projeto de educar cada vez mais pessoas em menos tempo e a maior distância? Mas a que necessidades formativas deveria atender e a que clientela ser dirigida a EAD? Em que casos seria ela aplicável e em que casos deveria ser afastada como inadequada? Ou deveria essa modalidade ser entendida como uma indicação universal?

Ainda que todas essas indagações esbocem um amplo percurso de reflexões, estudos e deliberações a ser percorrido, desde já elas indicam que, em se tratando da EAD on-line, a interrogação sobre o "que”

\footnotetext{
${ }^{5}$ No Brasil, data de 1996 o estabelecimento das bases legais para o desenvolvimento da EAD - que a equiparam formalmente à modalidade presencial, tanto do ponto de vista de sua validade quanto de sua abrangência a todos os níveis de ensino. A partir de 1999 começam a ser credenciadas para atuação em EAD as primeiras instituições de ensino. No entanto, só em 2005 o Ministério da Educação reconheceu a primeira universidade que tem por finalidade disseminar o ensino superior público em todo o país. Essa intenção apoiou-se no fato de apenas 11\% dos jovens entre 18 e 24 anos serem estudantes universitários. Três anos após seu reconhecimento, a Universidade Aberta do Brasil (UAB) reúne cerca de 200 mil estudantes. (Disponível em: <http://www.ufrj.br/docs/ em_pauta/UFRJempauta_16.pdf> Acesso em: 20 out. 2009).
} 
não pode vir separada da análise sobre o "quem”. Particularmente no caso do Brasil, se é inconteste que é preciso avançar na inclusão digital, ${ }^{6}$ não é menos verdadeiro que a apropriação das tecnologias de informação e comunicação (TIC) para fins de educação implica um espectro bastante específico de exigências que nem de longe se resumem ao simples treinamento para a mera manipulação de uma plataforma.

Assim, no que respeita não ao acesso a serviços bancários ou a informações de interesse público mas à formação de nível superior, quem é, de fato, aquele que se pretende (rapidamente) incluir? À pronta e entusiástica resposta “a todos!” objete-se, também de imediato, que muitas vezes as condições prévias para esse projeto de universalização não vêm sendo devidamente avaliadas. Considerando-se, por exemplo, as conclusões do V Indicador Nacional de Alfabetismo Funcional (2007), ${ }^{7}$ que revelam que apenas $28 \%$ da população possui habilidades plenas de lectoescrita, como pensar o potencial de inclusão do $3^{\circ}$ grau online? Pois não se pode esquecer que o uso acadêmico

${ }^{6}$ Na década de 1990, o otimismo dos órgãos governamentais brasileiros, era amplamente compartilhado pela União Europeia, que aclamava a “tecnologia para inclusão social”, e pelos Estados Unidos, que lançaram diversos projetos de inclusão digital (Warschauer, 2006). Mais do que uma questão terminológica, reinava a crença de que, conectando a população, principalmente a de países pobres, construir-se-ia um mundo de letrados digitais.

${ }^{7}$ Na pesquisa do INAF realizada pelo Instituto Paulo Montenegro, a população alfabetizada entre 15 e 64 anos foi classificada em três níveis: no nível 1, rudimentar, estão $25 \%$ da população indicada, que têm habilidade de leitura muito baixa, pois só são capazes de localizar informações simples em enunciados com uma só frase, num anúncio ou chamada de capa de revista, por exemplo; no nível 2, básico, encontram-se 40\% da população indicada, com habilidade básica para localizar informações em textos curtos (cartas, notícia curta etc.); no nível 3, pleno, estão 28\% da população brasileira, que têm habilidade plena, pois são capazes de ler textos mais longos, localizar mais de uma informação, comparar informações contidas em diferentes textos e estabelecer relações diversas entre eles. Além disso, 7\% da população indicada são de analfabetos absolutos (Instituto Paulo Montenegro, 2008). das TIC exige bem mais do que o simples domínio da linguagem digital - da escrita teclada.

De um ponto de vista geral, esses dados indicam que as desigualdades sociais que fizeram historicamente da plena capacidade de leitura e compreensão de textos um privilégio só tendem a se agravar se forem ignoradas as novas exigências decorrentes das TIC. ${ }^{8}$ De um ponto de vista mais específico, porém - e reconhecendo-se as dificuldades observadas na formação superior já na modalidade presencial -, é preciso indagar qual o grau de familiaridade e de amadurecimento no domínio das potencialidades expressivas e reflexivas da língua se estará disposto a definir como o mínimo necessário para a inclusão no $3^{\circ}$ grau on-line.

Outro aspecto, em nada acessório, da mesma indagação sobre o “quem” da EAD on-line é relativo à formação dos profissionais para essa modalidade. Também aqui há, evidentemente, questões técnicas relacionadas ao treinamento no uso dos equipamentos e recursos informáticos. Mas, esgotar-se-ia aí toda a dificuldade? Haveria, para além dos requisitos devidos ao intensivo apoio nas tecnologias informacionais e comunicacionais, exigências próprias à formação do educador a distância? Ou dever-se-ia entender que, colocadas à parte essas habilidades técnicas e metodológicas específicas, não há diferenças de vulto entre

${ }^{8}$ As exigências introduzidas pelas TIC recebem atenção especial da Universidade Aberta de Portugal (UAb), autodenominada um dos “mega-providers de e-learning europeus”, oferecendo cursos de graduação, mestrado e doutorado nas áreas de humanidades, das ciências da educação, das ciências exatas, tecnológicas e do ambiente, da gestão empresarial e das ciências sociais. Declarando sua preocupação em participar da construção da sociedade do conhecimento, a Universidade Aberta de Portugal afirma que essa contribuição se faz notar na proposta de inclusão digital, iniciada pela alfabetização digital: "O ensino online exige competências específicas por parte do estudante, pelo que todos os programas de formação certificados pela Universidade Aberta incluirão um módulo prévio, de frequência gratuita. Deste modo, os novos estudantes poderão adquirir competências antes da frequência do curso ou do programa de formação em que se inscreveram” (Universidade Aberta, s.d.). 
que se deve exigir da formação do educador, nas duas modalidades?

Decerto não existem respostas canônicas para quaisquer dessas questões, muito embora sua importância seja crucial, não só por sua evidente centralidade, mas sobretudo pelo fato de que elas vêm até aqui sendo correntemente menosprezadas. Sob o pano de fundo de tal descaso, o simples bom senso percebe o enorme desafio colocado à EAD para que a expertise que a incipiente área tão orgulhosamente proclama não se reduza a um mero tecnicismo.

Para os detratores da forma como, no Brasil, a EAD on-line vem sendo aplicada, a grande tarefa é justamente não incidir nos mesmos erros que caracterizaram a instituição da educação pública moderna, quando o excesso de entusiasmo pelos meios obnubilou a deliberação sobre os fins da formação humana. Para seus mais ardorosos defensores, no entanto, essa preocupação soaria inteiramente falsa: inspirados nas teorias da realidade virtual, que proclamam que as novas TICs estão engendrando uma verdadeira revolução, um novo tipo de sociedade e de humano, eles acreditam que as antigas referências já não têm tanto valor.

No entanto, tem-se por vezes a impressão de que o discurso de franca ruptura com o passado - e, de certa forma, com a sociedade tal qual ela é (ainda) hoje - resulta não só da crença de que os meios tecnológicos autorizariam um novo começo para o homem e a sociedade como da impossibilidade muito concreta de responder a todas as objeções que, de todas as partes e desde a perspectiva histórica, poderiam lhe ser feitas. Assim, é possível que a reedição da velha crença moderna na certa capacidade de autonomização da tecnologia - enfim em condições de viabilizar aquilo que a ação humana deliberada até então se tem mostrado incapaz de realizar - tenha sido uma condição senão necessária ao menos retoricamente conveniente para firmar a ideia de que a reintrodução da EAD, dessa vez na forma on-line, deveria se dar o mais imediata, intensiva e abrangentemente possível. Mas os benefícios implicados por tal concessão rapidamente se esgotarão, levando consigo todos os avanços que se tenha até aqui porventura alcançado, se não se buscar inverter essa disposição inicial - e, em vez de tentar entender a sociedade pelas lentes das promessas da EAD, buscar ler as promessas da EAD pelas lentes do que é histórica e culturalmente a sociedade, especialmente tal como registrado no patrimônio de reflexões sobre a formação humana.

Nesse sentido, a urgência torna-se agora a de investir no aprofundamento qualitativo - que permitirá, talvez, entender e qualificar melhor as rupturas que se acredita que devam ser realizadas e, sobretudo, aquelas que se deva evitar. E é para a construção de instrumentos conceituais que favoreçam tal elucidação que o presente artigo pretende contribuir.

\section{Um novo tipo antropológico?}

Deve-se certamente a Pierre Lévy a difusão da mais extrema tese sobre a revolução implicada pela informática. Para ele as TICs não apenas aboliriam o espaço e o tempo tal como os conhecemos como estariam na origem de novos modos de subjetivação e de socialização e mesmo de um novo tipo de sociedade e de democracia. E isso porque, coordenadas absolutas de toda significação e, pelo menos desde Kant, pilares da racionalidade humana, espaço e tempo não se modificam impunemente, mas acarretam profundas modificações na própria definição do humano.

Um novo espaço: Lévy (1997) ressalta a "plasticidade” que caracteriza o que, por oposição à referência espacial corriqueira, denomina "ciberespaço”. "Novo meio de comunicação que surge da interconexão mundial dos computadores” (p. 17), sob as bases dessa infraestrutura material da comunicação digital, o ciberespaço constitui-se em um "universo oceânico de informações”, que passaria a abrigar inclusive os seres humanos que navegam e alimentam esse universo. Garantidas pela virtualidade, a comunicação e a interação entre eles tornariam inconsistentes os dados clássicos da localização e da mobilidade, engendrando possibilidades ilimitadas de trocas. $\mathrm{Na}$ medida em que se revelaria capaz de desfazer antigos “territórios” e superar os limites até então incontorná- 
veis da relação humana, o ciberespaço se converteria, pois, no "espaço antropológico da inteligência e do saber coletivos", enfim "desterritorializados" e sem limites (1997, p. 17).

Um novo tempo: a “desterritorialização” incide igualmente sobre a lentidão do tempo histórico, que sempre mediu a vida das sociedades, e sobre o tempo psicológico, que estabelecia até então a experiência individual de construção de sentido. Aqui, a desconstrução anuncia-se como aceleração que traz, inevitavelmente, muitas rupturas. Segundo o autor, “o tempo pontual não anunciaria o fim da aventura humana, mas sim sua entrada em um ritmo novo que não seria mais o da história” (Lévy, 1993, p. 115).

Fora da história, mas fora também daquilo que, no sujeito, confere ao tempo psicológico toda sua morosidade, pois a nova "aprendizagem irá agora se acelerar a um ritmo bem mais rápido do que até então” (Lévy, 2001, p. 155). Uma aprendizagem enfim... livre do sujeito? De certa forma, parece mesmo que isso é proposto, na medida em que se aceite que o sujeito sempre foi pensado em relação a uma história social e a uma inserção cultural que o ciberespaço teria tornado obsoletas. Livre do peso das inconvenientes coordenadas que o tornavam mais lento e tropo, o novo humano descobre “a verdadeira educação e a verdadeira aprendizagem” como aquelas que "fundem todas as disciplinas em uma apreensão global para a qual a aprendizagem de si é tão importante quanto o conhecimento do mundo" (idem, ibidem, p. 156).

Restaria apenas explicar como a "aprendizagem de si”, se é que a devemos entender como autoformação, se daria a partir dessas novas bases, em que o enraizamento nos territórios humanos do corpo e da comunidade parecem superados pelo apoio em referências virtuais de um espaço sem territórios e de um movimento uniformemente acelerado que já não encontra resistências.

Por um lado, portanto, a perspectiva adotada é sem dúvida bastante confortável, na medida em que permite colocar entre parênteses o incômodo particularismo que sempre caracteriza as realidades humanas e sociais, a desafiar a intratável universalidade das formulações propostas pelo autor. Por outro lado, no entanto, é difícil conceber por que vias e em que circunstâncias o espaço social e o tempo humano se deixariam, de repente, tão facilmente abolir; e, em consequência, até que ponto poder-se-iam reconhecer nessa otimística perspectiva professores e alunos brasileiros que aderiram, por escolha ou por necessidade, à educação a distância.

Assim, descartadas as liberdades poéticas da science fiction, é preciso reconhecer que a proposta de Lévy não parece finalmente poder se apresentar como uma indicação universal. Para começar, na medida em que ela não inclui - et pour cause! - a hipótese de um processo de individuação/socialização inteiramente realizado no ciberespaço, isso é, na medida em que é impossível postular que a cibercultura possa de fato substituir, desde o início da socialização, a cultura tradicional, há que considerar que o mundo virtual está liminarmente cerrado àqueles que não se constituiram ainda, minimamente, como indivíduos socializados, capazes de lidar com as inúmeras deliberações e com os sofisticados processos de simbolização que a rede exige. Repare-se que a questão sequer é levantada por Lévy, para quem o cibercidadão é, antes de tudo, o adulto socializado na cultura tradicional.

Mas o cibercidadão não é tampouco o adulto de qualquer cultura ou de qualquer posição social. Tratase, na verdade, de um tipo antropológico altamente sofisticado: além do acesso à infraestrutura básica (equipamento e conexão) que hoje se difunde com grande rapidez, é preciso que ele tenha tempo disponível e um mínimo de escolaridade, além de condições para transitar comodamente por culturas e línguas diversas (evidentemente com domínio bastante bom do inglês). É claro que essa está longe de ser a condição de todo brasileiro adulto ou mesmo de todo brasileiro que aspira à inclusão no status que fornece entre nós o terceiro grau. Como não identificar, então, o brasileiro padrão com o “excluído”, que "está desconectado. [E, assim sendo,] não participa da densidade relacional e cognitiva das comunidades virtuais e da inteligência coletiva” (Lévy, 1997, p. 238)? 


\section{A volta ao tempo do prodígio}

Para Lévy, tanto quanto para aqueles que acreditam poder aplicar fielmente suas ideias à realidade de nosso país, as exceções assinaladas não chegam a se constituir um problema maior, posto que ele está trabalhando com "possibilidades". Considerando a perspectiva monocular para a qual a expansão da cibercultura é o destino inexorável de toda a humanidade, Lévy nada faz além de projeções daquilo que, hoje ausente, deverá se tornar, de forma mais ou menos rápida, realidade. É inegável o caráter progressista desse investimento em uma proposta de universalidade que, hierarquizando culturas e grupos de indivíduos segundo sua adesão a um projeto único, só vê como problema a maior ou menor lentidão do processo de conversão. Mas, como assinala Castoriadis sobre o projeto de racionalidade moderno,

Se todas as tribos humanas, após seu longo período de perambulação pelas florestas selvagens da pré-civilização, estivessem agora a caminho de se unir nas clareiras da Aufklärung, de onde nós, os primeiros a chegar, as saudaríamos amigavelmente, à medida que viessem se aproximando, os problemas certamente seriam bem diferentes [...]. (Castoriadis, 1987, p. 284)

Do ponto de vista, digamos, ideológico, é portanto possível desde já avançar que, longe de romper com o passado, a EAD se assenta sobre um progressismo típico da modernidade. Lévy não nega essa filiação ainda que o patrimônio que reivindique para si seja cuidadosamente escolhido entre os melhores ideais da Revolução Francesa, que teriam enfim se tornado possíveis com essa outra revolução, a da cibercultura.

Em contraste com a ideia pós-moderna de declínio das ideias das Luzes, defendo que a cibercultura pode ser considerada como herdeira legítima (ainda que longínqua) do projeto progressista dos filósofos do século XVIII. De fato, ela valoriza a participação em comunidades de debate e de argumentação, na linha direta das morais igualitárias, encoraja uma forma de reciprocidade essencial nas relações humanas. Desenvolveu-se partir de uma prática assídua das trocas de informações e de conhecimentos, que os filósofos das Luzes consideravam como sendo o principal motor para o progresso. E, portanto, se algum dia fomos modernos, a cibercultura não seria pós-moderna, estaria antes dando continuidade aos ideais revolucionários e republicanos de liberdade, igualdade e fraternidade. Apenas na cibercultura esses valores encontram-se encarnados em dispositivos técnicos concretos: na era das mídias eletrônicas, a igualdade é realizada como possibilidade de que cada um emita para todos. A liberdade é objetivada por meio de programas de codificação e do acesso transfronteiriço a diversas comunidades virtuais. A fraternidade, enfim, transparece na interconexão mundial. (Lévy, 1997, p. 235)

Mas não consistiria o progressismo exatamente nisso - na visão inteiramente positivada da evolução que, ao mesmo tempo em que realiza a história, com ela rompe radicalmente? Mais, portanto, do que os ideais de liberdade, igualdade e fraternidade desde há tanto perseguidos, é o projeto de um tempo e um espaço revolucionados, engendrados na e pela ruptura com o tempo e o espaço conhecidos, o que garante a grande continuidade com a modernidade e, em particular, com os ideais da Revolução Francesa. Tal como nos sonhos dos revolucionários de 1789, tempo e espaço apareceriam, na cibercultura, como verdadeiras construções que fixam os quadros de uma nova realidade humana e social.

A fórmula do progressismo, nos dois casos, é bastante simples e totalmente baseada na confiança nas novas possibilidades de domínio ampliado da realidade. No caso exemplar da Revolução Francesa, as expectativas foram inicialmente depositadas na ação legislativa, supostamente capaz de introduzir, por si só, o que uma estudiosa do período, Mona Ozouf, denominou de "prodígio revolucionário": um tempo que não estaria comprometido com a história mas que gozaria do "privilégio da instantaneidade” que caracteriza a atividade demiúrgica da política (Ozouf, 1989, p. 10). No entanto, ao contrário do que sustentou Ozouf, a história se encarregou de demonstrar que o voluntarismo do pensamento utópico não atingiu, na modernidade, apenas os radicais jacobinos, mas tomou bem mais correntemente a forma do culto ao progresso e à técnica. 
Mas o "milagre revolucionário” não pode, também (e de maneira decerto bem mais rica de alusões para a realidade brasileira...), traduzir-se por uma confiança ilimitada nos novos meios técnicos capazes de decuplicar o poder da ação humana, livrando-a da lentidão do tempo comum? Traduzida em termos pedagógicos, essa confiança tomaria, então, a forma de "uma instrução acelerada que deve obter em pouco tempo efeitos de massa", e que tem no episódio da fabricação do salitre uma das sua primeiras e mais expressivas ilustrações. (Do Valle, 1997, p. 132)

Assim, aos poucos, o entusiasmo empenhado na fabricação das leis e na transformação dos hábitos reconverte-se ao terreno educacional. E, de fato, a modernidade foi pródiga nesses exemplos de confiança extremada nos meios sempre prontamente investidos na criação de novidades pedagógicas capazes de vencer a lentidão tipicamente humana e de encurtar as distâncias que se estabelecem nas sociedades modernas. Na França revolucionária, o episódio da fabricação da pólvora para as guerras que o novo regime enfrentava forneceu um primeiro modelo das intervenções no gênero. Como relata um observador, J. B. Biot, o rápido treinamento de lideranças que, em seguida, se encarregavam de difundir a técnica nas províncias serviu para propagar a confiança nos meios instrucionais:

Uma instrução curta e simples, difundida com um inconcebível ativismo, fez de uma difícil arte uma prática vulgar [...]. Os resultados desse grande movimento teriam permanecido inúteis se as ciências não tivessem sido secundadas por novos esforços [...]. Cidadãos vindos de todos os departamentos foram enviados a Paris a fim de se instruírem no fabrico de armas e de salitre. Realizaram-se cursos rápidos sobre o tema, que foram chamados de revolucionários. Eles contribuíram pouco para o movimento geral que salvou a República; mas obtiveram um efeito não menos importante: o de colocar em evidência a surpreendente facilidade dos franceses para aprender as ciências e as artes. (Biot apud Julia, 1989, p. 292) ${ }^{9}$

${ }^{9}$ Observe-se que o relato (de 1803) não vem da parte de um entusiasta das primeiras horas da Revolução Francesa; os primeiros
Outro elemento que compõe a herança moderna da EAD consiste na redução da formação ao controle irrestrito das informações sociais - ou, em outras palavras, na assimilação da educação à instrução. ${ }^{10} \mathrm{O}$ projeto cultural utópico que alimentara a Revolução Francesa - a possibilidade de conceder a todos o livre acesso a um conjunto de conhecimentos organizados que possuiria, por si só, poder formativo - parece renovado em certas expectativas que fazem da $\mathrm{EAD}$ on-line o locus de uma cidadania ampliada, de nova concepção de democracia, em ruptura com o passado.

Outrora, as injustiças sociais impediam essa igualdade de base e faziam da cidadania um privilégio. Mas ela agora é o bem comum que a instrução garantirá, sem falhas nem omissões. Entretanto, para além desse patrimônio coletivo, o degrau a que cada um ascenderá nessa carreira será aquele que a natureza marcou por si só, em suas faculdades, como o termo de seus esforços. (Romme, 1889, p. 189)

Fica claro que, ao se visar a comunicação ou mesmo a troca de informações, em vez da formação, isto é, da autoalteração, ganha-se em objetividade o que se perde em complexidade. A justa avaliação das perdas e ganhos do processo não é, no entanto, tarefa simples, já que o investimento educacional implica a possibilidade de manter o discurso idealizado e de postergar a cobrança dos resultados: ação visada é sempre um projeto - uma "possibilidade”.

cursos tiveram lugar em fevereiro de 1794 e em seguida, em julho do mesmo ano, a École de Mars é fundada.

${ }^{10}$ A articulação instrução e educação não é evidentemente um fenômeno exclusivamente brasileiro. Ao discutir sete modelos de educação a distância, Otto Peters (2004) mostra que todos eles convergem para a intenção de "estimular nossa criatividade, quando planejamos sistemas instrucionais apropriados” (p. 83). A excessiva preocupação em utilizar os recursos especiais e ambientes amigáveis oferecidos pela nova mídia tem sido uma constante e revela que o enaltecimento dos meios muitas vezes deixa à sombra as interrogações que deveriam ser feitas acerca do aprendizado e, de modo mais geral, da formação dispensada. Tapscott (1998) critica o que denomina de "instrucionismo", que segundo o autor levaria à “imbecilização” do jovem, assim como “a tentação da cópia” tão presente no uso da internet. 
Um só tempo escolar para formar um só aluno, que pode responder pelo abstrato nome de Razão pública, instância universal e superior a planar acima de toda individualidade, acima da sociedade, supremo produto de uma ação pedagógica que perfaz o tempo e realiza as leis. (Do Valle, 1997, p. 138)

Ali, como na EAD on-line, essa postergação se apoia na expectativa inteiramente positivada do tempo: na suposição de que, à medida que passa, ele realiza essa contagiante construção denominada "progresso”. A postergação apoia-se, pois, em uma sucessão temporal. Mas ela tem forçosamente por fiadora uma figuração que permite provar, por antecipação, das maravilhas da promessa de progresso. Ela depende, portanto, da coexistência espacial que a imagem de ambientes de exceção faculta - esses mesmos ambientes que, no futuro, deverão se generalizar. No passado, a escola pública foi um desses ambientes, convocando simbolicamente do futuro toda uma nova geração de cidadãos emancipados; na atualidade, é a rede que inaugura a vocação comum que o tempo se encarregará de realizar.

Tanto quanto a Revolução Francesa, a EAD online engendraria, pois, "novas condições de espaço público” (Farge, 1989, p. 304). Entretanto, na atualidade, esse espaço conjugaria, de forma que os antigos revolucionários não poderiam conceber, as vantagens da imediatez com os benefícios da promessa: nisso consiste o milagre operado pelos avanços tecnológicos da atualidade. No entanto, o prestígio dos meios não introduziria também, subliminarmente, uma visão mágica dos efeitos do trabalho pedagógico, empurrando para bem longe a revelação de seus limites?

\section{O quem da modernidade}

Afirmamos que o progressismo característico da modernidade - o ideal de ruptura com o tempo e o espaço tradicionais e de inauguração de um novo tempo e espaço - é, mais do que o projeto político de igualdade, liberdade e fraternidade, a perspectiva ideológica de base sobre a qual se assenta hoje o projeto de EAD on-line.
Seria preciso, contudo, ir mais além, indagando se, também do ponto de vista antropológico, a tríade revolucionária não perderia lugar para outra influência mais poderosa; em outras palavras, se não seria no radical isolamento do sujeito on-line que as construções antropológicas modernas encontrariam seu mais evidente prolongamento.

Pois, se fosse preciso resumir em poucas palavras a originalidade da construção antropológica que a modernidade nos legou, dir-se-ia que o período criou, para a posteridade, o modelo do sujeito isolado, do indivíduo que se habituou a pensar a própria existência no modo do isolamento, de uma quase completa independência em relação ao tempo e ao espaço social em que foi engendrado, cada vez mais próximo daquilo que dele mais se distancia e cada vez mais afastado de tudo quanto está próximo - modelo psicológico tão semelhante àquele do ser conectado...

Não que se pretenda eludir as contribuições da Antiguidade - na figura clássica do "filósofo fora da cidade" que caracteriza o ideal platônico de sabedoria ou, no período helenístico, quando da decadência da democracia, nos novos ideais de conduta individual; tampouco que se ignorem as marcas indeléveis introduzidas pela tradição cristã - que desloca para a intimidade da experiência religiosa as exigências do discernimento moral; mas a verdade é que em nenhum outro período da história humana se concebeu, como na modernidade, a emancipação intelectual e moral como conquistas - e, ademais, como aquisições absolutamente individuais.

Não é, pois, tão surpreendente que se estabeleça a hipótese dessa direta filiação que faz com que o cibercidadão contemporâneo seja simplesmente impossível sem o duplo isolamento em que passa a se construir a identidade moderna: em relação ao outro - mundo, materialidade, mas também sociedade e relações sociais - e em relação a si mesmo - a seu corpo, seus impulsos, sua sensibilidade imediata. É este, em última análise, o sentido que toma, do ponto de vista antropológico, o controle ampliado sobre o tempo e o espaço: a perda das referências que guiavam o sujeito encarnado mas que funcionavam, também, como limites para sua atuação. 
Pode-se fixar de forma mais ou menos precisa a origem dessa operação de desenraizamento - cujo primeiro termo é forçosamente a redução do humano à sua dimensão cognitiva - na invenção do sujeito cartesiano. A reconstrução da noção de relação consigo mesmo e a separação radical entre alma e corpo operadas por Descartes dão início, sem com ela se identificarem inteiramente, à instituição do "homem de ciência” moderno - tipo antropológico destituído de particularidades empíricas, de sua inserção social e histórica tanto quanto de sua psique, mas que é a imagem mesma da conquista do saber seguro e sujeito a comprovação universal (Castoriadis, 1982, p. 38-39). E, sem dúvida, sob a égide do cartesianismo, a certeza pode enfim fazer-se experiência de uma consciência que, radicalmente individual, nada fica a dever à coletividade; contudo, para que esse saber possa se oferecer, a partir daí, como paradigma e fundamento de toda certeza, o preço da individualidade é igualmente a destituição de qualquer particularismo.

No que tange, porém, à crítica do cartesianismo, todo cuidado é pouco para que se evitem as imprecisões e os equívocos transformados em lugares comuns do pensamento educacional da atualidade: decerto não foi Descartes o primeiro a associar a busca de um saber válido a uma experiência íntima ao contrário, é longa a tradição que, no Ocidente, reconhece no pensamento uma condição paradoxal da existência humana, caracterizada exatamente por uma espécie de alheamento do mundo (Arendt, 2005, p. 71).

Muito embora os gregos não conhecessem a noção de consciência (no sentido algo polissêmico, mas predominantemente cognitivo) que a modernidade consagrará, sua língua reserva uma grande variedade de termos e expressões para indicar diferentes formas de relação consigo mesmo. Da épica homérica à poesia jônico-eólica, dos diálogos socráticos à tragédia democrática, a prática de interlocução consigo mesmo marca a crescente exigência do logos em sua luta pela significação (Cassin, 2004, p. 261-262).

Porém, esse autoexame é, no contexto corrente da cultura grega antiga, invariavelmente marcado por uma referência externa. Mais adiante, ao instalar a deliberação pública no cerne da vida da polis, a democracia fez do logos uma experiência compartilhada (Heródoto, LXXX); e, buscando a medida inscrita na própria natureza, a filosofia desde cedo havia estabelecido a comunicabilidade e a verificabilidade como fundamentos máximos da razão, que Platão identificará às formas puras da verdade e da justiça.

\section{[...] e não seriam, pensamento e discurso, um só, com a ressalva de que ao diálogo interior da alma com ela mes- ma, sem voz, demos [igualmente] o nome de pensamento? (Cassin, 2004, p. 261-262)}

É, então, apenas no período helenístico - e, logo, de decadência dos valores democráticos e crise da ideologia cívica - que o autoexame é reapropriado pelas escolas morais para designar a solidão do indivíduo que, em seu isolamento, examina sua conduta e sua pessoa.

Contudo, não é excessivo afirmar que Descartes introduz uma radicalidade que jamais havia marcado a experiência do pensamento, moral ou cognitivo. Se antes a exigência crítica incluía o questionamento de valores que o indivíduo devia à sua inserção no mundo comum dos sentidos e a seu pertencimento cultural - valores, por isso mesmo, reconhecidos como constituintes da experiência de cada humano -, agora o sujeito pensante acredita só poder se erguer em ruptura total com as marcas de sua corporeidade, de sua inserção no tempo e no espaço. É essa a fonte do que vimos de denominar "progressismo". No que se refere a Descartes, afirma Arendt, a

\footnotetext{
[...] desconfiança bem moderna em relação ao equipamento sensorial e cognitivo do homem o leva a identificar com mais clareza do que jamais havia sido feito antes os atributos da res cogitans com certas características que os antigos não ignoravam, mas que passam a ter, pela primeira vez, uma importância capital. Em primeiro plano, a autonomia, o fato de que o ego "não tem necessidade de nenhum lugar e não depende de nenhuma coisa material”, em seguida a independência em relação ao mundo, o fato de que, pela
} 
introspecção, o filósofo possa "fazer de conta que não tinha corpo e que não havia nenhum mundo, nenhum lugar onde ele estivesse”. (Arendt, 2005, p. 74)

Mas não se pode ignorar que, para o filósofo moderno, essa liberação em relação ao tempo e ao espaço define uma experiência de solidão que é a condição para a acuidade cognitiva e autenticidade moral; por mais que ele pretenda prolongá-la, essa situação sempre será encarada como parcial - e compõe o folclore do personagem filosófico sua capacidade de aí permanecer indefinidamente, para prejuízo de outras marcas de sua "humanidade”. Nesse sentido, ao pretender que a ruptura com o espaço e com o tempo que também a caracterizam deve ensejar a constituição de uma nova sociabilidade, a EAD on-line vai mais além do que a modernidade jamais imaginou.

\section{O sujeito isolado e o ser conectado}

Anunciado pelas mais distintas perspectivas filosóficas, o sujeito moderno emerge como um dos primeiros produtos da forte confluência de interesses e disposições que levaram, na modernidade, à redescoberta da razão humana. Pode-se dizer que esse sujeito começa a ser engendrado sob a influência do Iluminismo e de sua crítica radical aos dogmas e preconceitos instituídos por uma tradição que, como os homens das Luzes não deixaram de observar, desde a Antiguidade não hesitava em se comunicar através dos sentimentos, buscando tocar os corações e as almas. Pretendendo fugir a essa herança, a educação moderna descobriu a sua vocação de só falar à razão - que cabia, agora, instruir.

E não foram suficientes os protestos de Rousseau: sob a égide de um projeto de racionalização que o cartesianismo já proclamara e que o liberalismo tomará como sua própria essência, subordinam-se todas as dimensões humanas àquela que mais parece corresponder ao seu ideal de controle. Modulado pela aspiração ao domínio ilimitado que as perspectivas de desenvolvimento da ciência e da técnica propiciavam, o conhecimento ganha nova acepção e se transforma em ideal humano, virtude social e princípio de identidade.

A rigor, as bases do programa se encontravam, como já dissemos, consignadas em Descartes: é preciso desencantar o mundo para melhor dominá-lo. Para isso, o homem tem à sua disposição a arma do entendimento puro:

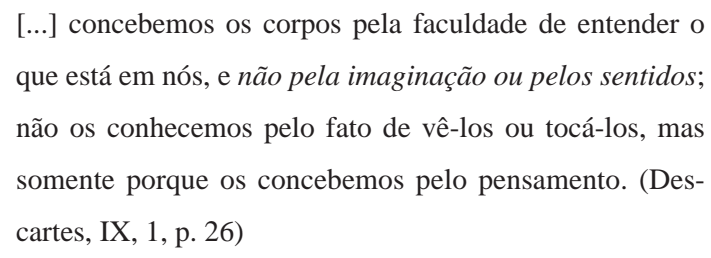

A subordinação da experiência da imaginação e dos sentidos à cognição é decerto a prova contundente da radicalidade a que estavam destinados os tempos modernos; mas o sujeito conectado vê nisso uma obviedade. Contudo, na modernidade o que se busca é um ideal de conhecimento perfeito, de que nosso contemporâneo - mais voraz e, talvez, mais volúvel já não compartilha. Para os modernos, o entendimento exige o controle não só dos sentimentos, mas das sensações que o humano ordinariamente experimenta a partir de um modo de se deixar afetar sensorialmente que é, ele próprio, marcado pela cultura. Esse ideal de conhecimento desdobra, pois, o sujeito em um observador exterior e neutro, já que é enfim capaz de dominar-se. Os contemporâneos decerto aprenderam a lição: e assim, para eles, tudo que importa conhecer deve ser convertido em informação - que já não figura, eternizada e inteira, em uma suma perfeita, mas circula profusa e efêmera na rede. Não se solicita mais do saber, como na grande utopia moderna, que ele transforme e emancipe os indivíduos e sociedades: tudo que se espera é que ele conecte o indivíduo. O ideal de comunicação da atualidade desfaz o sujeito em participações múltiplas e sempre provisórias. Jamais o sujeito foi tão isolado: apesar disso - ou exatamente em virtude dessa condição - jamais foi tão importante, para qualquer sujeito em uma sociedade, que ele prove estar ligado, conectado, pronto a absorver as estonteantemente rápidas informações que a rede propicia. 
O desdobramento do sujeito moderno, tal como proposto por Locke, ${ }^{11}$ não consistiu em mais do que um simples voltar-se sobre si mesmo. Mas ainda aí há desdobramento, porquanto o sujeito da re-flexão que Locke descreve, isto é, do exame de sua própria atividade mental, é um “outro” tornado, por assim dizer, objeto para si. Pouco importa que mais tarde ele seja dado, por Kant, como puro paralogismo: o sujeito lockiano inaugura a condição desencarnada e artificial que é própria da razão moderna mas que se tornou atributo essencial de nossa integração mundana - ontem, de nossa adesão à sociedade urbano-industrial; hoje, ao ciberespaço.

O sujeito do desengajamento e do domínio da razão tornou-se para nós uma figura familiar da modernidade. Poder-se-ia quase dizer que ele se tornou uma das maneiras de nos interpretarmos, da qual temos dificuldade em nos desfazer [...]. Esse sujeito atinge seu pleno desenvolvimento [...] em Locke e nos pensadores das Luzes que ele influenciou [...]. A característica desse sujeito é atingir o domínio pelo desengajamento. (Taylor, 1998, p. 212)

Porém, é evidente que, para os filósofos modernos, o desengajamento não deveria implicar perda senão daquilo que não podiam mais aceitar que constituísse o sujeito. Em vista da nova humanidade que vislumbravam, esse desprendimento deveria traduzirse em surplus de racionalidade; e, esta, em capacidade ampliada de aquisição do saber. Em contraposição, na atualidade poder-se-ia afirmar que cabe aos meios técnicos o alargamento das capacidades cogntivas a níveis jamais pensados. No entanto, ainda assim, ou talvez por isso mesmo, a reforma moderna terá sido necessária para permitir que o humano rompesse as amarras que o prendiam ao aqui e agora, para fazer com que ele experimentasse de forma continuada e corriqueira o afastamento do mundo sensível. Sem isso, como poderia ele usufruir tão intensamente dos

${ }^{11}$ É preciso não negligenciar a influência de John Locke sobre a formação desse novo tipo antropológico. Para E. Balibar (1998), ele deve ser dado, mais do que Descartes, como o grande protagonista da invenção da consciência moderna. benefícios da tecnologia, e aceitar tão rapidamente habitar um mundo virtual? E isso porque o que a modernidade busca reformar é a própria natureza humana. Tal como em Locke, em Kant a razão nada tem de imediatamente natural. Ainda que se constituindo em atributo universal, isto é, naquilo que os homens têm naturalmente em comum, a razão autônoma é antes uma vitória sobre a animalidade: por isso, é somente através da cultura - e propriamente através da educação, pela qual “o homem será 'disciplinado' (domado), ‘cultivado’ (instruído), ‘civilizado’ (prudente) e 'moralizado' (apto a escolher bons fins, isso é, fins universalizáveis)" (Cassin, 1999, p. 115) - que a razão se descortinará.

\section{O locus do prodígio: espaço público e o ciberespaço}

É claro que o projeto de controle das disposições naturais, dos sentidos, da psicologia individual e das paixões - em suma, o projeto de neutralização da condição empírica que marca a existência humana só atinge a plena inteireza como conceito filosófico abstrato e modelo antropológico adaptado aos usos da racionalização da sociedade. Isso não implica, porém, que o sujeito cognoscente seja invenção solitária de filósofos: pelo contrário, ele é, antes de qualquer outra coisa, o primeiro produto de um mundo que não somente se quer emancipado dos antigos dogmas e, assim, desencantado, mas que, aos poucos, se vai voltando cada vez mais inteiramente para o progresso material, em nome do qual os indivíduos são chamados a abdicar da vida pública - da "liberdade dos antigos". Não foi de uma só vez, nem sem muitas indas e vindas que a máxima liberal ${ }^{12}$ se impôs no mundo moderno: hoje, entretanto, Benjamin Constant se orgulharia de perceber a tranquilidade com que a sociedade aceita como uma das maiores aquisições do progresso a possibilidade de se esquivar da participação política em nome de uma mais "livre” fruição da vida privada (Constant, 1980).

12 Não é à toa que tantos defendem, para a realidade brasileira, o "ideal" de livre participação nas eleições... 
Uma dupla tendência descreve a ambiguidade irredutível da modernidade - período em que, após séculos de desaparecimento, o espaço público volta a ser objeto de instituição, ainda que sob a contínua ameaça que representa a ambição de progresso material ilimitado. Como definiu com sutileza e argúcia Castoriadis, desde o início a modernidade encontra-se permanentemente trabalhada por essas duas significações contraditórias que, no entanto, se “autocontaminam”: a aspiração pela emancipação, concretizada pela intensa interrogação e pelas lutas democráticas; e o ideal de controle racional, encarnado pelo capitalismo (1992, p. 21). Sob essas bases, o novo espaço que a modernidade pretendia instalar, locus da igualdade, da participação democrática e da construção republicana, tornou-se, paradoxalmente, o cenário em que se travou uma outra grande revolução: a do lento esvaziamento da própria política, em razão do obscurecimento das fronteiras entre o público e o privado. Assim, ter-se-ia finalmente dissolvido a ambiguidade moderna: os espaços desde então constituídos espelham uma nova aspiração, a expectativa de uma estranha unicidade, descrita pelo composto sui generis do público e do privado. Em outras palavras, busca-se um novo espaço que, liberado de limites antes intransponíveis, espelhe com fidelidade o âmago das expectativas privadas; mais ainda, acredita-se que a política possa se converter nessa livre circulação das ideias, dos projetos, das expectativas e trocas - amplificação daquilo a que a perspectiva individual já dá acesso: não seria o ciberespaço o amálgama há tanto esperado?

Arendt analisou as consequências do desaparecimento, no mundo moderno, das esferas privada e pública, anteriormente constitutivas da existência humana: o estabelecimento, no seio dessa experiência mundana de, por um lado, uma "privaticidade" esvaziada e muda e, por outro, uma prática social que, não mais permitindo a experiência da política da pluralidade e da singularização que o mundo antigo conhecera, se reduz a comportamento estereotipado (Arendt, 1987, p. 48), a conduta uniforme e plenamente racionalizável:
A uniformidade estatística não é de modo algum um ideal científico inócuo, e sim o ideal político, já agora não mais secreto, de uma sociedade que, inteiramente submersa na rotina do cotidiano, aceita pacificamente a concepção científica inerente à sua própria existência. (idem, ibidem, p. 53)

Tal como define Arendt, na Antiguidade o espaço público permitia a emergência da singularidade porque, rompendo com a rigidez dos compostos tradicionais, enseja a instituição de identidades que não se definem a priori, como é o caso daquelas que resultam inteiramente das relações familiares; ora, por permitir a emergência da individuação e, ao mesmo tempo, por se constituir basicamente em uma experiência de construção comum e de partilha, o espaço público também engendrava a pluralidade - a coexistência de diferentes identidades reunidas em projeto comum, de múltiplas perspectivas, a partir das quais se aprecia um mesmo objeto, de diversos posicionamentos a partir dos quais se avalia uma única situação.

Por isso, o espaço público não definia, segundo Arendt, uma atividade qualquer entre outras, senão aquilo que a autora denominou de ação humana - atividade de criação do novo, "política por excelência”, na medida em que é "criação de novos corpos políticos”; mas plenamente humana, porque desempenhada diretamente entre humanos, que assim se recriam, ao recriar sua sociedade (Arendt, 1987, p. 188).

No espaço público que somente a ação humana pode engendrar, o sujeito inventava-se como singularidade à medida mesmo que se descobria membro de uma pluralidade: no entanto, é insofismável que, na modernidade, a vida comum se tornou menos e menos ocasião de compartilhamento de experiências para enfatizar crescentemente, como já observamos, o isolamento do sujeito no seio da massa. Perdido em uma igualdade que não revela originalidade mas uniformidade, o sujeito moderno substituiu a ação pelo comportamento estereotipado. Espera-se, contudo, que seu herdeiro, o cibercidadão, recupere o ânimo e a iniciativa perdidos, encontrando na interatividade um novo horizonte de atuação individual, pois no ciberespaço - ao menos no que toca à terminologia - se aceita 
facilmente a impregnação da ação pela atividade: o que se leva em conta já não é a natureza política do ato compartilhado, capaz de engendrar novas realidades comuns, mas justamente a possibilidade de prosseguir uma trajetória pessoal sem maiores obstáculos ou delongas. É que, em uma experiência de construção comum, o outro, em sua singularidade, decerto não é só - é mesmo raro que o seja - ocasião de enriquecimento, porém correntemente obstáculo que se interpõe à maneira pessoal de entender o mundo e de significá-lo. No ciberespaço, imagina-se que o outro colaborativo jamais se apresente como aquilo que a mim resiste: se as comunidades virtuais têm algo de idílico, é porque se espera que tenham - ao menos em teoria - a pureza que os modernos desejaram um dia projetar na figura do bon sauvage. Só que, agora, a idealidade já não é ruptura com o presente que mergulha no passado da civilização, mas justo seu contrário: é o salto direto para o futuro permitido pelo avanço técnico. Em uma palavra, o que se chama de interação - a livre comunicação entre humanos - é uma conquista eminentemente tecnológica, não é mais do que a consequência da interatividade alcançada pelo aperfeiçoamento tecnológico do suporte.

\section{Uma questão aberta}

Estamos assistindo ao nascimento de uma geração de jovens inovadores, antenados, entendedores do poder da mídia, que aprendem por meio da interação. A informação não é apenas consumida. Ela também é produzida pelos jovens. [...] Esses jovens têm autoconfiança e autoestima. Sabem que seu futuro não está nas mãos de governos ou empresas. Valorizam os direitos individuais, como a privacidade e a liberdade de expressão. E mais: querem ser tratados com justiça. Há um traço cultural marcante que faz com que eles queiram dividir uma parte da riqueza que ganham. (Tapscott \& Williams, 2006, p. 39)

Nosso exame das bases antropológicas da EAD on-line deparou-se, assim, com duas figuras da modernidade que denunciam o quanto essa nova modalidade, pretendendo revolucionar tempo e espaço e criar uma nova sociedade para um novo humano, nada mais faz do que recuperar os velhos sonhos e os antigos ideais modernos. Mas já não temos dúvidas de que a influência que o período exerceu e continua exercendo sobre a educação on-line não se limita às expectativas revisitadas: muitas são as razões para que nos interroguemos se o sujeito conectado e o ciberespaço não são, a rigor, a manifestação paroxística dos vícios que a modernidade não soube evitar.

Entretanto, não se pretende afirmar qualquer fatalidade, mas antes prevenir sobre o que, por detrás dos discursos exageradamente otimistas e das promessas por demais generosas, se esconde: o obscurecimento da dimensão coletiva de que a individualidade não pode se passar sem se esvaziar inteiramente, tanto quanto a perda da referência corpórea e telúrica a um aqui e agora sem o qual a virtualidade não é senão delírio.

Os desafios colocados para a EAD on-line são, assim, a realização de uma ruptura: tudo está em saber em relação ao quê, ou melhor, em vista de quem.

\section{Referências bibliográficas}

ALMEIDA, Fernando. Educação e informação. 2. ed. São Paulo: Cortez/Autores Associados, 2005.

ARENDT, Hannah. A condição humana. Rio de Janeiro: Forense Universitária, 1987. . La vie de l'esprit. Paris: PUF/Quadrige, 2005.

BALIBAR, Étienne. Identité et différence. L’invention de la conscience. Paris: Seuil, 1998.

BRASIL. Ministério da Educação. Censo do Ensino Superior 2006. Brasília: MEC/INEP, 2007. Disponível em: <http://www.inep.gov. br/superior/censosuperior>. Acesso em: 30 nov. 2008.

. Sobre educação a distância. Disponível em: <http://

uab.capes.gov.br/index.php> e <http://portal.mec.gov.br/seed/ index.php?option=com_content\&task=view\&id=61 $>$. Acesso em: 27 nov. 2008.

CASSIN, Barbara. Aristóteles e o lógos. Contos da fenomenologia comum. São Paulo: Loyola, 1999.

Le grec pour “conscience”: rétroversions. In:

(Org.). Dictionnaire européen des philosophes. Paris: Seuil/Le Robert, 2004. p. 261-262. 
CASTORIADIS, Cornelius. Epilegômenos a uma teoria da alma que se pôde apresentar como ciência In: . Encruzilhadas do

labirinto. Rio de Janeiro: Paz e Terra, 1982. p. 38-39.

. A polis grega e a criação da democracia. In:

Encruzilhadas do labirinto II. Domínios do homem. Rio de Janeiro: Paz e Terra, 1987.

. A época do conformismo generalizado. In:

Encruzilhadas do labirinto III. O mundo fragmentado. Rio de Janeiro: Paz e Terra, 1992. p. 13-26.

CONSTANT, Benjamin. De la liberté chez les Modernes. Paris: Pluriel, 1980.

DESCARTES, René. Méditations, $I X, 1$, 26. In: Oeuvres

complètes. Paris: Gallimard, s.d. (Coleção La Pléiade.)

DO VALLE, Lílian. A escola imaginária. Rio de Janeiro: DP\&A, 1997.

FARGE, Arlette. L'enfant, la famille et la Révolution. Paris: Olivier Orban, 1989.

HERÓDOTO. Histoire. 3. v. Paris: Charpentier, 1930. (Trad. brasileira: História. Rio de Janeiro: Ediouro, s.d. Disponível em: <http://remacle.org/bloodwolf/historiens/herodote/index.htm>. Acesso em: 29 maio 2009.)

INSTITUTO PAULO MONTENEGRO. Inaf 2007 mostra evolução da educação no Brasil. Disponível em: <http://www.ipm. org.br/ipmb_pagina.php?mpg=4.02.01.00.00\&ver=por $>$. Acesso em: 26 nov. 2008.

JULIA, Dominique. Les trois couleurs de la Révolution. Paris : Belin, 1989.

LÉVY, Pierre. As tecnologias da inteligência. Rio de Janeiro: Editora 34, 1993.

. Cibercultura. Rio de Janeiro: Editora 34, 1997.

A conexão planetária. São Paulo: Editora 34,

2001.

OZOUF, Mona. L’homme régénéré. Essais sur la Révolution française. Paris: Gallimard, 1989.

PETERS, Otto. A educação a distância em transição: tendências e desafios. São Leopoldo: Editora UNISINOS, 2004.

ROMME, G. Rapport sur l'instruction publique considérée dans son ensemble, 20 décembre de 1792. In : GUILLAUME, James.
Procès Verbaux du Comité d'instruction publique de la Convention. Paris : s.ed., 1889. p. 347-369.

TAPSCOTT, Don. Geração Net. São Paulo: Makron Books, 1998.

.; WILLIAMS, Anthony D. Wikinomics. Rio de Janeiro: Nova Fronteira, 2006.

TAYLOR, Charles. Les sources du moi. La formation de l'identité moderne. Paris: Seuil, 1998.

UNIVERSIA. Expansão da EAD segue tendência mundial. 2004.

Disponível em: <http://www.universia.com.br/html/noticia/noticia_clipping_bhcfa.html>. Acesso em: 27 nov. 2008.

UNIVERSIDADE ABERTA DE PORTUGAL. Sobre a Universidade Aberta. Disponível em: <http://www.univ-ab.pt/ua/sobre. php>. Acesso em: 30 nov. 2008.

WARSCHAUER, Mark. Tecnologia e inclusão social. São Paulo: Editora SENAC, 2006.

ESTRELLA BOHADANA, doutora em comunicação social pela Escola de Comunicação da Universidade Federal do Rio de Janeiro (UFRJ), é professora da linha de pesquisa de Tecnologia de Informação e Comunicação e Processos Educacionais do Programa de Pós-Graduação em Educação da Universidade Estácio de Sá. Publicação recente: Lições introdutórias de filosofia da educação (Rio de Janeiro: ControlC, 2006). Pesquisa atual: “Inovações tecnológicas, cibercultura e educação”.E-mail: ebohadana@ terra.com.br

LILIAN DO VALLE, doutora em educação pela Universidade de Paris V - René Descartes, é professora titular de filosofia da educação da Universidade do Estado do Rio de Janeiro (UERJ). Publicação recente: Enigmas da educação (Belo Horizonte: Autêntica, 2008). Pesquisa atual: "Para além do sujeito isolado: modos antigos e contemporâneos de presença e ação”. E-mail: lilidovalle@gmail.com

Recebido em abril de 2009 Aprovado em julho de 2009 
educação, focalizando o modo como nele se apresenta o subcampo composto pelos estudos sobre a temática política educacional. Para tanto, parte de breve abordagem histórica sobre a constituição da pós-graduação no Brasil, com ênfase nas políticas voltadas para a pós-graduação em educação.

Considera-se que os cursos de mestrado e doutorado representam um lugar privilegiado de produção do conhecimento, dada a centralidade que neles deve assumir a pesquisa científica. Procura-se analisar a inserção e a evolução da pesquisa educacional nesse processo, o que, por seu turno, é usado como estratégia com vista a apontar o lugar dos estudos sobre o tema política educacional nos programas de pós-graduação em educação, particularmente no Nordeste.

Palavras-chave: pós-graduação e pesquisa; política educacional; Brasil; Nordeste.

\section{Postgraduate studies in Brazil,} research in education and studies on educational policy: contours of the constitution of an academic field

This article problematises specificities that surround the academic field of education, focusing on the way in which the sub-field composed of studies on educational policy is represented. To that end, it starts with a brief historical introduction to the constitution of postgraduate studies in Brazil, with emphasis on policies directed at postgraduate studies in education. Masters' and doctoral courses are considered to represent a privileged place in the production of knowledge, given the centrality which scientific research should assume in them. We seek to analyse the insertion and evolution of educational research in that process which, in its turn, is used as a strategy with a view to indicate the place of studies on educational policy in programmes of postgraduate studies in education, particularly in the northeast region of Brazil.

Key words: postgraduate studies and research; educational policy; Brazil; Northeast.

El postgrado en Brasil, la pesquisa en educación y los estudios sobre la política educacional: los contornos de la constitución de un campo académico

Este artículo trata especificamente los problemas que rodean el campo académico de la educación, focalizando el modo como en él se presenta el subcampo compuesto por los estudios sobre la temática politica educacional. Para esto, parte de un breve abordaje histórico sobre la constitución del postgrado en Brasil, con énfasis en las politicas dirigidas para el postgrado en educación. Se considera que los grupos de máster y doctorado representan un lugar privilegiado de producción del conocimiento, dado a la centralidad que en ellos debe asumir la pesquisa científica. Se procura analizar la inserción y la evolución de la pesquisa educacional en este proceso, lo que, por su turno, es usado como estrategia con vista a apuntar el lugar de los estudios sobre el tema política educacional en los programas de postgrado en educación, particularmente en Nordeste.

Palabras claves: postgrado y pesquisa; política educacional; Brasil; Nordeste.

Estrella Bohadana e Lílian do Valle

\section{O quem da EAD}

Em curto espaço de tempo, a educação a distância (EAD) passou de recurso marginal a menina dos olhos das políticas públicas e das ações empresariais. Hoje, não é possível desconsiderar o impacto que a introdução da EAD online vem causando em nossas formas correntes de conceber e de praticar a educação e a comunicação. Seus mais ardorosos defensores proclamam que as tecnologias de informação e de comunicação estão engendrando um novo tipo de sociedade e de humano. No entanto, tem-se a impressão de que o discurso de franca ruptura com o passado resulta não só da crença exacerbada nos meios tecnológicos, como da impossibilidade de responder as objeções que lhe poderiam ser feitas. Nesse sentido, torna-se agora urgente investir no aprofundamento teórico - que permitirá, talvez, entender e qualificar as rupturas que devam ser realizadas e aquelas que devam ser evitadas. É para a construção de instrumentos conceituais que favoreçam tal elucidação que o presente artigo pretende contribuir.

Palavras-chave: EAD on-line; cibercidadão; modernidade e tecnicismo; formação humana e democracia; sujeito isolado.

\section{The whom of distance education}

In a short period of time, distance education was transformed from a marginal resource to the apple of the eye of public policies and business actions. Today one cannot ignore the impact that the introduction of e-learning has caused on our current ways of conceiving and practicing education and communication. Its most ardent defenders proclaim that information and communication technologies are engendering a new type of society and human being. However, one has the impression that the discourse of evident rupture with the past results not only from an exaggerated belief in technological resources but also from the impossibility of responding to the objections that could arise. In that sense, it is now urgent to invest in further theoretical studies, which will perhaps allow us to understand and qualify the ruptures that must 
occur and those that should be avoided. The purpose of this article is to contribute to the construction of conceptual tools that promote such an understanding.

Key words: e-learning; cybercitizen; modernity and technicism; human formation and democracy; isolated subject.

\section{El quien de la educación a distancia}

En un espacio corto de tiempo, la educación a distancia (EAD) pasó de un recurso marginal a un importante recurso de las políticas públicas y de las acciones empresariales. Hoy, no es posible no considerar el impacto que la introducción de la EAD on-line viene causando en nuestras formas corrientes de concebir y de practicar la educación y la comunicación. Sus más ardorosos defensores proclaman que las tecnologías de información y de comunicación están engendrando un nuevo tipo de sociedad y de humano. Sin embargo, se tiene la impresión de que el discurso de franca ruptura con el pasado resulta no sólo de la creencia severa en los medios tecnológicos, como de la imposibilidad de responder a las objeciones que podrian ser hechas. En este sentido, ahora se vuelve urgente investir en la profundidad teórica - que permitirá, tal vez, entender y calificar las rupturas que deban ser realizadas y aquella que deban ser evitadas. Es para la construcción de instrumentos conceptuales que favorezcan el esclarecimiento que el presente artículo pretende contribuir.

Palabras claves: EAD on-line; ciberciudadano; modernidad y tecnología; formación humana y democracia; sujeto aislado.
Sílvia Andreis Witkoski

\section{Surdez e preconceito: a norma da fala e o mito da leitura da palavra falada}

Falar sobre surdez e preconceito é narrar uma das interfaces do ser surdo. Dentre o imenso leque que o envolve, o artigo traz para discussão a norma da fala e o mito da leitura da palavra falada, por considerar que ambos legitimam uma série de práticas oralistas, afetando pejorativamente a construção da identidade do ser surdo e seu direito a uma comunicação e formação significativa. Em nome de uma pseudointegração entre surdos e ouvintes, mascaram-se os preconceitos em relação à surdez e aos surdos, ao implicitamente não aceitar sua diferença linguística, de percepção do mundo e forma de ser. Essa discussão é construída essencialmente a partir do resgate de muitas vivências dos próprios surdos, a fim de trazer à tona as suas nuanças, desvelando alguns dos discursos que legitimam esses preconceitos, buscando desnudar as implicações dolorosas que geram na vida dos surdos.

Palavras-chave: surdez; preconceito; Libras.

Deafness and prejudice: the norm of speech and the myth of lip reading To talk about deafness and prejudice is to describe one of the interfaces of being deaf. Among the many things that this involves, this article puts in discussion the norm of speech and the myth of "lip reading" because they both legitimate a series of oral practices, affecting negatively the identity of being deaf and the right to communicate in a meaningful way. In the name of a "pseudo-integration" of deaf with hearing people, prejudices in relation to deafness and the deaf are disguised, when implicitly not accepting their linguistic difference, their perception of the world and way of being. The discussion is built essentially on many experiences of deaf people themselves, in order to bring out the nuances, and in so doing, reveal some of the discourses which legitimize the prejudices, whilst seeking to lay bare the painful implications that these generate in the life of deaf people.

Key words: deafness; prejudice; sign language (Libras).

Sordera y prejuicio: la norma del habla y el mito de la lectura de la palabra hablada

Hablar sobre sordera y prejuicio es narrar una de las interfaces del ser sordo. En medio al inmenso abanico que lo envuelve, el artículo trae para la discusión la norma del habla y el mito de la lectura de la palabra hablada, por considerar que ambos legitiman una serie de prácticas orales, afectando peyorativamente la construcción de la identidad del ser sordo y su derecho a una comunicación y formación significativa. En nombre de una seudo integración entre sordos y oyentes, se disfrazan los prejuicios en relación a la sordera y a los sordos, al implicitamente no aceptar su diferencia lingüistica, de percepción del mundo y de su forma de ser. Esta discusión es construida esencialmente a partir del recate de muchas vivencias de los propios sordos, con el intuito de mostrar sus matices, descubriendo algunos de los discursos que legitiman esos prejuicios, buscando descubrir las implicaciones dolorosas que generan en la vida de los sordos. Palabras claves: sordera; prejuicio; Libras. 